\title{
Effects of Continuous and Pulsating Water Jet on CNT/Concrete Composite
}

\author{
Vladimir Foldyna $1,2,{ }^{*}$ - Josef Foldyna ${ }^{2}$ - Dagmar Klichova ${ }^{2}$ - Jiri Klich ${ }^{2}$ - Petr Hlavacek ${ }^{2}$ \\ - Lenka Bodnarova ${ }^{3}$ - Tomas Jarolim ${ }^{3}$ - Katerina Mamulova Kutlakova ${ }^{1}$ \\ 1 VSB-Technical University of Ostrava Nanotechnology Centre, Czech Republic \\ ${ }^{2}$ Institute of Geonics of the ASCR, Department of Material Disintegration, Czech Republic \\ 3 Brno University of Technology, Faculty of Civil Engineering, Czech Republic
}

This paper presents first results of the study of the resistance of carbon nanotube concrete composite (CNT/concrete composite) to the action of continuous and pulsating water jets. The experiments oriented at the determination of erosion effects of pulsating and continuous water jets impinging the surface of reference (concrete) and CNT/concrete composite samples were performed. Tested samples were characterized by X-ray powder diffraction and scanning electron microscope. Samples were exposed to pulsating and continuous water jets at various operating parameters. Erosion effects of pulsating and continuous jets were evaluated in terms of material removal rate. The possible influence of addition of CNTs to the concrete on its resistance to the action of continuous and pulsating water jets is discussed in the paper. The experiments proved that CNT/concrete composite exhibits higher resistance than reference concrete to the action of both pulsating and continuous water jet under the given testing conditions.

Keywords: pulsating and continuous water jet, CNT/concrete composite, material removal

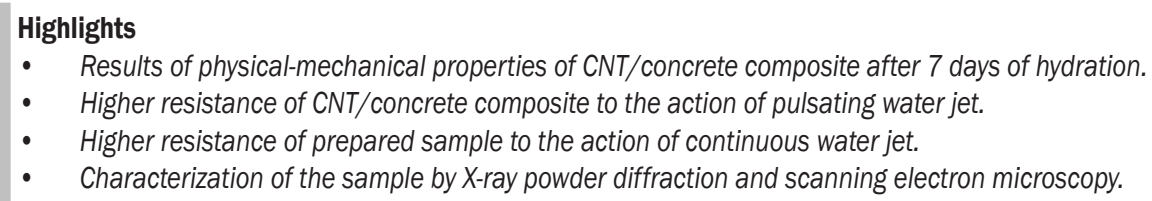

\section{INTRODUCTION}

In past years, concrete was used worldwide in the field of civil engineering [1]. The main advantages of cement based composites are ease for construction, room temperature setting, low cost and the ready availability of properties and performance data for design and construction [2] and [3]. The major weaknesses of traditional cement based material is low tensile strength and the fact that it can be easily cracked, which affect durability, safety and strength of concrete structures [4] and [5]. Tensile strength of plain concrete is between $2 \mathrm{MPa}$ to $8 \mathrm{MPa}$ [6]. Many types of fillers were used to improve cement based composites properties, especially its toughness [7]. Used fillers increased tensile strength, but has only slight effect on initiation of micro-cracks because of volumetric changes due to high autogenous shrinkage stresses and delaying only macro-cracks [8]. Therefore, there is a big effort to adapt to the flexural and tensile mechanical properties of the matrix in order to improve the fracture and damage resistance of concrete. To deal with disadvantages of reinforcement of cementitious material mentioned above the reinforcement is typically provided at the micro and milli-scale using microfibers and macrofibers. Concrete matrix however exhibit flaws at the nanoscale, where traditional fillers are not effective [9].

With spreading of nanotechnology into various technologies, it comes also its application in concrete composites [10]. Nanomaterials provide unique multifunction properties due to their size. New types of reinforced polymers, nanoparticles $\left(\mathrm{TiO}_{2}, \mathrm{Fe}_{2} \mathrm{O}_{3}\right.$, $\mathrm{SiO}_{2}$ ) and especially carbon nanotubes (CNTs) are suitable micro-fillers for these composites, because of their high strength at atomic scale [11].

Nanomaterials can have following beneficial effects on the microstructure and properties of cement based composites:

- filling in free space between cement grains and preventing flow of water,

- forming crystallic centers and speeding up cement hydration process,

- supporting creation of small crystals such as $\mathrm{Ca}(\mathrm{OH})_{2}$ and uniform agglomeration of C-S-H products,

- $\quad$ speeding up pozzolanic reactions, which consume $\mathrm{Ca}(\mathrm{OH})_{2}$ and produce additional C-S-H gel,

- enhancing contact area, which increase bonding strength between aggregates and cement compound. 
CNTs are one of the most promising fillers to improve concrete nanocomposite properties. Carbon nanotubes are hexagonal nets formed from rolled up graphene into cylindrical nanostructured tubes. Some of them are ended with fullerene hemispheres. There are two main groups of CNTs: single-walled carbon nanotubes (SWCNTs) and multi-walled carbon nanotubes (MWCNTs). SWCNTs consist from single rolled up graphene sheet and MWCNTs are composed of two or more layers of graphene. MWCNTs are cheaper to prepare so they are used more often than SWCNTs [12]. Moreover, MWCNTs offer better reinforcement in cement composites. MWCNTs have many applications in industry (such as electronic materials, medicine and chemistry) due to their exceptional chemical and physical properties (thermal conductivity, electrical conductivity, low specific weight, and high resistance to corrosion) [13] and [14].

The possible improvement in both physical and mechanical properties of cement-based nanocomposites could lead to the new generation of ultra-high performance concretes that would, for example, allow reduction of the dimensions of structural elements, which would lead to further economic and environmental benefits. Therefore, the joint research program was started at the Institute of Geonics and Brno University of Technology to investigate the influence of nanoparticles on properties of cement based composites.

The technology of a high-speed water jet is commonly used in repair of concrete structures due to its selectivity; if properly adjusted, it removes only a corroded or degraded layer of concrete and saves any compacted material. The selective properties of water jets can also be used in determination of concrete quality. The measure of concrete quality can be its resistance to effects of high speed water jets. This property is common to both pulsating and continuous water jets; however, a higher volume of concrete can be removed by pulsating jet under the same working conditions [15].

First results of the study aimed at determination of possible influence of addition of CNTs to the concrete on its resistance to the action of continuous and pulsating water jets are presented and discussed in the paper.

\section{METHODS}

\subsection{Preparation of Testing Samples}

Multi-walled carbon nanotubes from Yurui (Shanghai) Chemical Co., Ltd. were used for preparation of CNT/ concrete composite in presented work. They were prepared by chemical vapour deposition with purity more than $95 \%$. Their properties are summarized in Table 1.

Table 1. Properties of MWCNTS

\begin{tabular}{ll}
\hline Properties & \\
\hline Internal diameter & approx. $5 \mathrm{~nm}$ to $12 \mathrm{~nm}$ \\
\hline Outer diameter & approx. $30 \mathrm{~nm}$ to $50 \mathrm{~nm}$ \\
\hline Length & $10 \mu \mathrm{m} \mathrm{to} 20 \mu \mathrm{m}$ \\
\hline Bulk density & $0.22 \mathrm{~g} \cdot \mathrm{cm}-3$ \\
\hline True density & $2.1 \mathrm{~g} \cdot \mathrm{cm}^{-3}$ \\
\hline
\end{tabular}

Defined volume $(0.564 \mathrm{~g})$ of naphthalene-based superplasticizer with polymeric chain, which was used as a surfactant, was mixed with 0.1 liter of water and $0.141 \mathrm{~g}$ of CNTs ( 0.003 wt. \% of cement weight) in rosette vessel. Then, the suspension was ultrasonified for $10 \mathrm{~min}$ and, after homogenization, the solution was added into 2.3 liters of water. The mixture of small quarry stone sand $0 / 4 \mathrm{~mm}$ (locality Zabcice), rough-crushed stone $4 / 8 \mathrm{~mm}$ (locality Olbramovice), rough-crushed stone $8 / 16 \mathrm{~mm}$ (locality Olbramovice) and Portland cement CEM I $42.5 \mathrm{R}$ from cement plant Mokra (Heidelberg Cement Czech Republic) was added into mixer and mixed for 1 min without addition of water.

Then, prepared solution of water, superplasticizer and CNTs was added to the mixture and mixed for another 2 minutes. Total volume of prepared concrete with CNTs was $15 \mathrm{dm}^{3}$ in Table 2. Reference material was prepared same way only without CNTs. The composition of reference and CNT concrete is given in Table 2.

Table 2. Composition of reference and CNT/concrete

\begin{tabular}{lcc}
\hline Material & Reference & CNT/concrete \\
\hline CNTs & - & $0.141 \mathrm{~g}$ \\
\hline Superplasticizer & $0.564 \mathrm{~g}$ & $0.564 \mathrm{~g}$ \\
\hline Cement & $4.7 \mathrm{~kg}$ & $4.7 \mathrm{~kg}$ \\
\hline Small quarry stone sand $0 / 4 \mathrm{~mm}$ & $10.6 \mathrm{~kg}$ & $10.6 \mathrm{~kg}$ \\
\hline Rough-crushed stone $4 / 8 \mathrm{~mm}$ & $4.7 \mathrm{~kg}$ & $4.7 \mathrm{~kg}$ \\
\hline Rough-crushed stone $8 / 16 \mathrm{~mm}$ & $12.5 \mathrm{~kg}$ & $12.5 \mathrm{~kg}$ \\
\hline Water & $2.4 \mathrm{~kg}$ & $2.4 \mathrm{~kg}$ \\
\hline
\end{tabular}

\subsection{Characterization of Samples}

Concrete was not fully hydrated, hydration was stopped after 7 days and selected physical and mechanical properties of samples were determined. In addition, their characterization by scanning electron 
microscopy (SEM) and X-ray powder diffraction (XRPD) was also performed.

\subsubsection{Physical and Mechanical Properties}

Tests of consistency of fresh concrete and compressive strength and flexural strength of hardened concrete after 7 days were carried out. The test of consistency was performed in accordance with the standard EN 12350-2 [16]. The compressive strength of hardened concrete was measured in accordance with EN 123903 [17], and flexural strength in accordance with EN 12390-5 [18]. Measured physical-mechanical properties of reference and CNT/concrete test specimens are summarized in Table 3.

\subsubsection{Scanning Electron Microscopy}

SEM analysis and characterization of testing specimens by ASPEX PSEM Explorer did not reveal any significant differences in the structure of reference and $\mathrm{CNT} /$ concretes. The only conclusion made from the SEM analysis is that the samples were not fully hydrated, as can be seen in Fig. 1. Again, the influence of the CNTs on the hydration process should be studied using SEM on cement paste with addition of CNTs only.

\subsubsection{X-Ray Powder Diffraction}

Samples were characterized by XRPD patterns measured under $\mathrm{CoK} \alpha$ irradiation $(\lambda=1.789 \AA)$
Table 3. Physical-mechanical properties of reference and CNT/ concrete sample

\begin{tabular}{lcc}
\hline Properties & Reference & CNT/concrete \\
\hline Consistency [mm] - degree & $20-\mathrm{S} 1$ & $10-\mathrm{S} 1$ \\
\hline Flexural strength [MPa] & 8.98 & 8.38 \\
\hline Compressive strength [MPa] & 42.29 & 43.75 \\
\hline
\end{tabular}
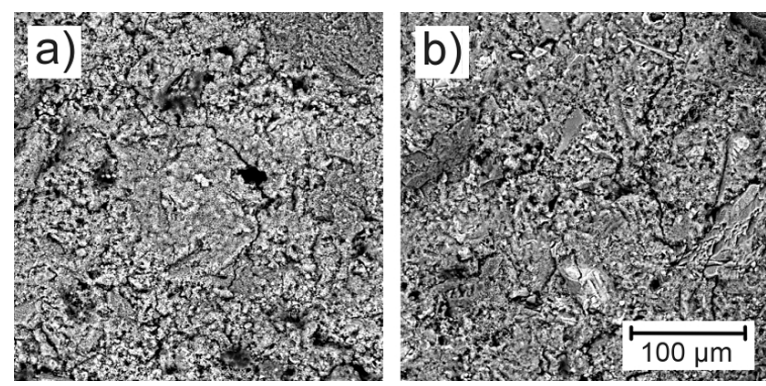

Fig. 1. SEM image of a) reference, and b ) CNT/concrete

using the Bruker D8 Advance diffractometer (Bruker AXS) equipped with a fast position sensitive detector VÁNTEC 1.

As one can see in Fig. 2, quartz and non-hydrated phases of Portland cement overshadowed the hydrated phases.

Presence of tricalcium and dicalcium silicate indicates that concrete samples were not fully hydrated. However, the results indicate that the influence of the CNTs on the hydration process has to be studied on cement paste with addition of CNTs

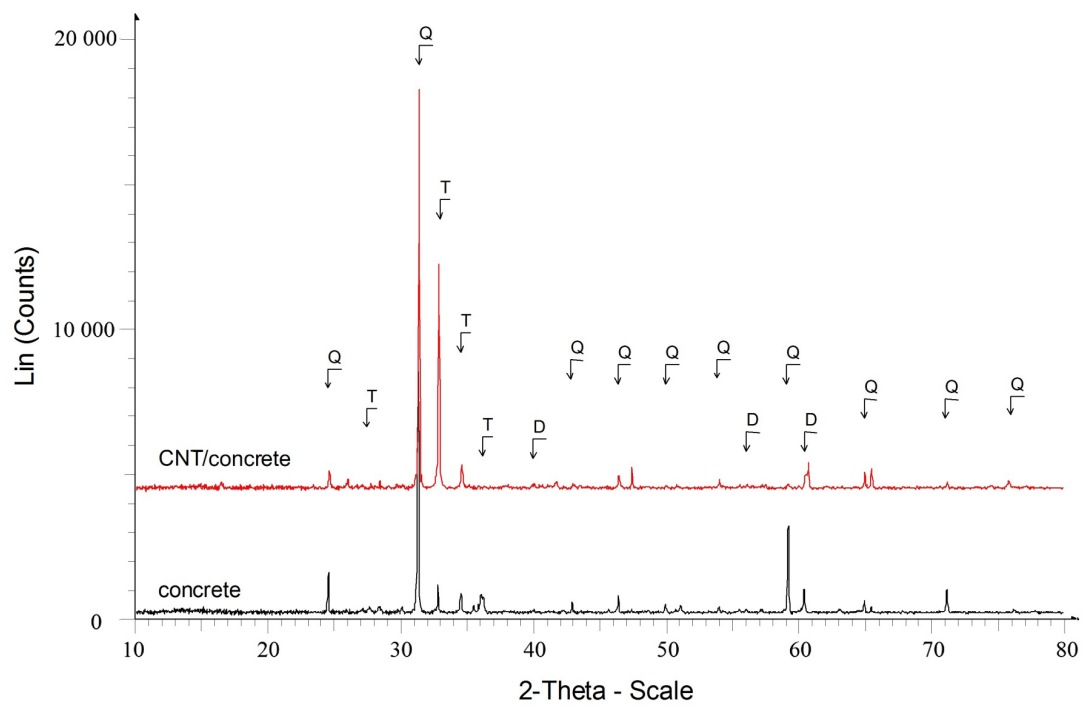

Fig. 2. XRPD patterns of reference concrete and CNT/concrete composite. (Q is Quartz, D Dicalcium silicate, and T Tricalcium silicate) 
only to avoid overshadowing of hydrated phases by quartz.

\section{EXPERIMENTAL}

The experiments oriented at the determination of erosion effects of pulsating (PWJ) and continuous (CWJ) water jet impinging the surface of reference (concrete) and CNT/concrete composite samples were performed in the Waterjet laboratory of the Institute of Geonics. Disintegration effects of high-speed water jets were tested and evaluated to compare their effects on CNT/concrete composite and reference samples.

\subsection{Laboratory Equipment and Testing Conditions}

The experimental assembly for water jetting tests consisted of the high-pressure plunger pump Hammelmann HDP 253 (delivering up to $67 \mathrm{l} \cdot \mathrm{min}^{-1}$ at the maximum operating pressure of $160 \mathrm{MPa}$ ), a pulsating water jet head (with a $20 \mathrm{kHz}$ ultrasonic generator) installed on the arm of the ABB IRB 6640 robot. The PWJ head (high-speed water jet) was moved over the tested sample by the robot using various traversing velocities. The commercially available nozzle StoneAge Attack (nozzle diameter d was $1.9 \mathrm{~mm}$ ) was used in the experiment to generate both continuous and pulsating jets. Two values of operating pressure $p 20 \mathrm{MPa}$ and $40 \mathrm{MPa}$ were used in experiments. Standoff distances $S O D$ of $25 \mathrm{~mm}$ (at $20 \mathrm{MPa}$ ) and $35 \mathrm{~mm}$ (at $40 \mathrm{MPa}$ ) were determined in previous experiments to be optimal for given testing conditions. Traversing velocity $v_{T R}$ was changed from $10 \mathrm{~mm} \cdot \mathrm{s}^{-1}$ to $80 \mathrm{~mm} \cdot \mathrm{s}^{-1}$ during tests at $20 \mathrm{MPa}$ and from $50 \mathrm{~mm} \cdot \mathrm{s}^{-1}$ to $160 \mathrm{~mm} \cdot \mathrm{s}^{-1}$ during tests at $40 \mathrm{MPa}$. Proprietary method of the generation of the pulsating liquid jet based on the generation of acoustic waves by the action of the acoustic transducer on the pressure liquid and their transmission via pressure system to the nozzle (so called acoustic generator of pressure pulsations) was used to generate PWJ. Acoustic generator of pressure pulsations used in experiments generated pressure pulsations at the frequency of about $20 \mathrm{kHz}$ (exact frequency depends on the actual geometrical configuration of the generator), amplitude of vibrations of the acoustic transducer was set to 7 $\mu \mathrm{m}$. More details on the method of PWJ generation used in the experiments can be found elsewhere [19] and [20]. Schematic drawing of the experimental setup is given in Fig. 3.

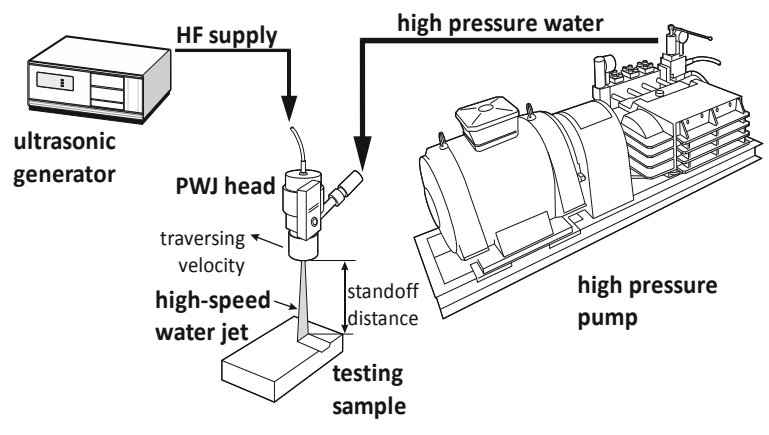

Fig. 3. Schematic drawing of the experimental setup

\subsection{Experimental Procedure}

Erosion effects of PWJ and CWJ on CNT/concrete composite and reference (concrete) samples exposed to their action under various operating parameters were evaluated in terms of material removal rate. Grooves created by the action of the jets were measured using MicroProf FRT optic profilometer. Subsequently, 2D and 3D images of grooves were created and the volume of removed material $V$ was determined using SPIP software. Evaluated length of the groove $l$ was $20 \mathrm{~mm}, 56$ grooves were processed in total. The resistance of the samples to the action of PWJs and CWJs was evaluated in terms of material removal rate $\Delta V$ (see in Eq. (1)) which was determined using following formula:

$$
\Delta V=\frac{V \cdot v_{T R}}{l} \quad\left[\mathrm{~mm}^{3} \cdot \mathrm{s}^{-1}\right]
$$

\section{RESULTS}

Results of evaluation of erosion effects of PWJ and $\mathrm{CWJ}$ on $\mathrm{CNT} /$ concrete composite and reference samples are presented in form of graphs in Figs. 4 and 5. Material removal rate is dependent on a type of water jet. Material removal rate of CWJ remains almost constant with increasing traversing velocity in given range, whereas PWJ exhibits increasing of material removal rate at higher traversing velocities in given range, which can be seen in Figs. 4 and 5.

Photographs and 3D images of selected examples of grooves created by the CWJ and PWJ in reference and CNT/concrete composite samples can be seen in Figs. 6 to 9. Concrete with carbon nanotubes exhibits higher resistance to $\mathrm{CWJ}$ and $\mathrm{PWJ}$ than reference samples. Major difference between material removal rates can be observed in Fig. 7. 


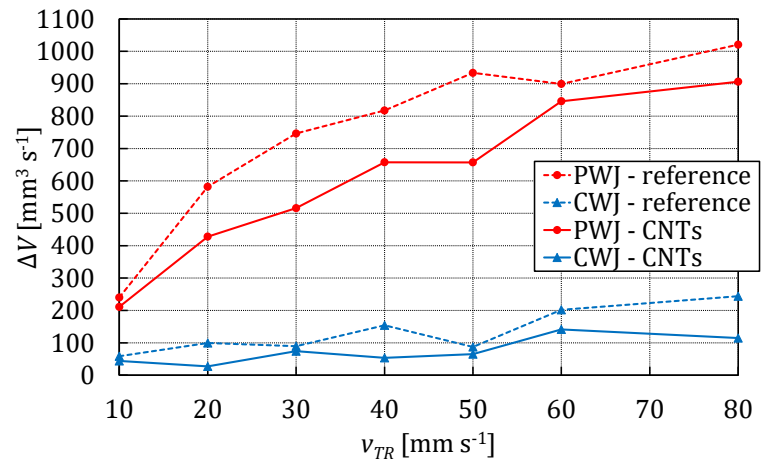

Fig. 4. Influence of traversing velocity $v_{T R}$ on the material removal rate $\Delta V$ in $C N T$ /concrete composite and reference concrete exposed to CWJ and PWJ generated at $20 \mathrm{MPa}$

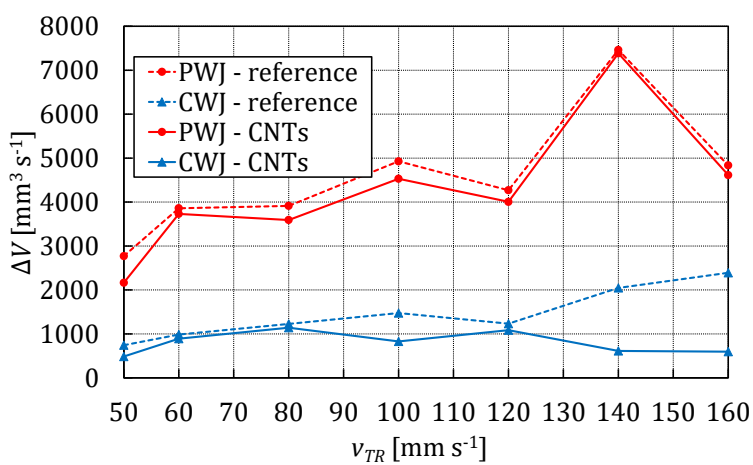

Fig. 5. Influence of traversing velocity $v_{T R}$ on the material removal rate $\Delta V$ in $C N T /$ concrete composite and reference concrete exposed to CWJ and PWJ generated at $40 \mathrm{MPa}$

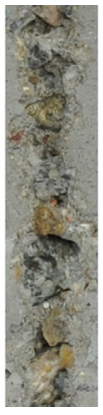

a)

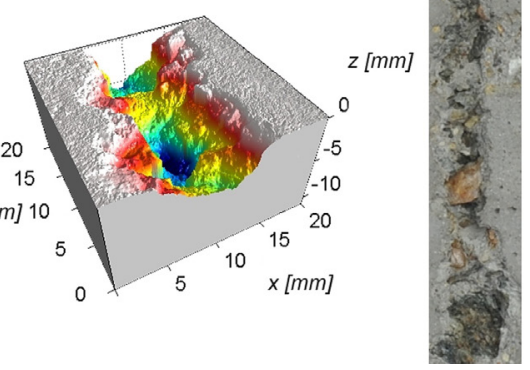

b)

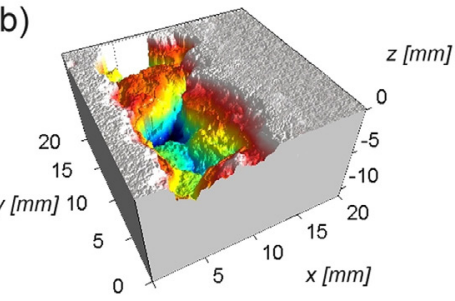

Fig. 6. Photograph and $3 D$ view of the groove created by a) the PWJ in reference and b) CNT/concrete composite sample (operating pressure $p=20 \mathrm{MPa}$, traversing velocity $v_{T R}=30 \mathrm{~mm} \cdot \mathrm{s}^{-1}$ )

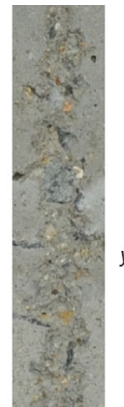

\section{a)}

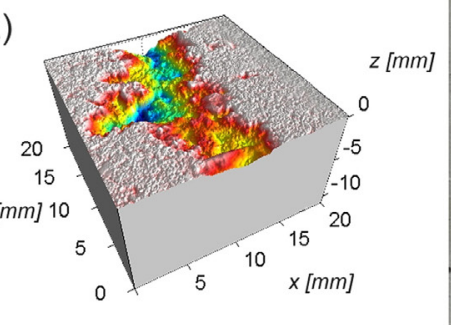

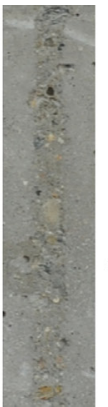

b)

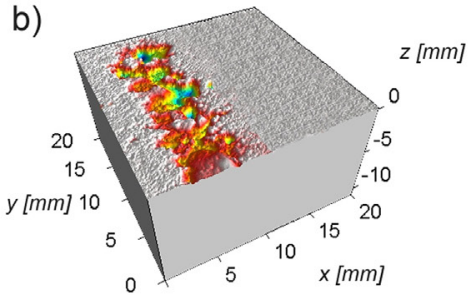

Fig. 7. Photograph and $3 D$ view of the groove created by a) the CWJ in reference and, b) CNT/concrete composite sample (operating pressure $p=20 \mathrm{MPa}$, traversing velocity $\mathrm{v}_{T R}=40 \mathrm{~mm} \cdot \mathrm{s}^{-1}$ )
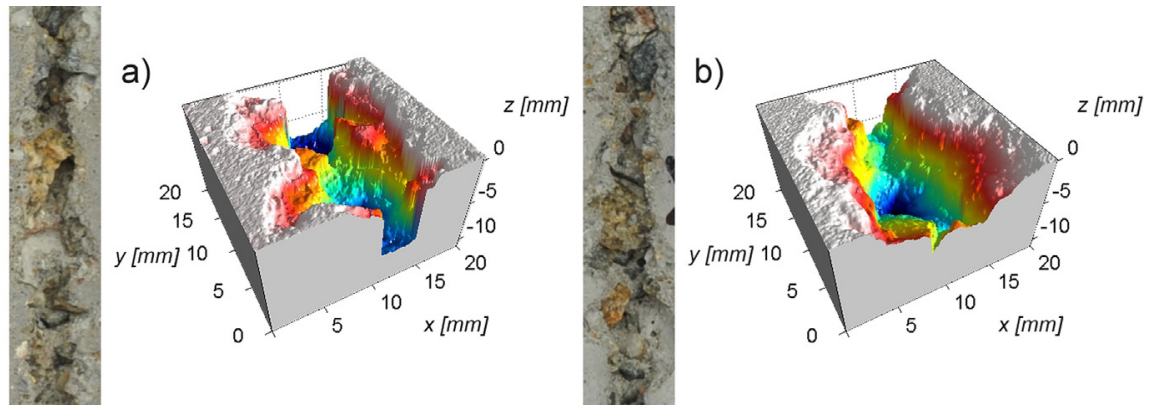

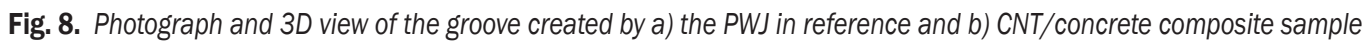
(operating pressure $p=40 \mathrm{MPa}$, traversing velocity $v_{T R}=100 \mathrm{~mm} \cdot \mathrm{s}^{-1}$ ) 

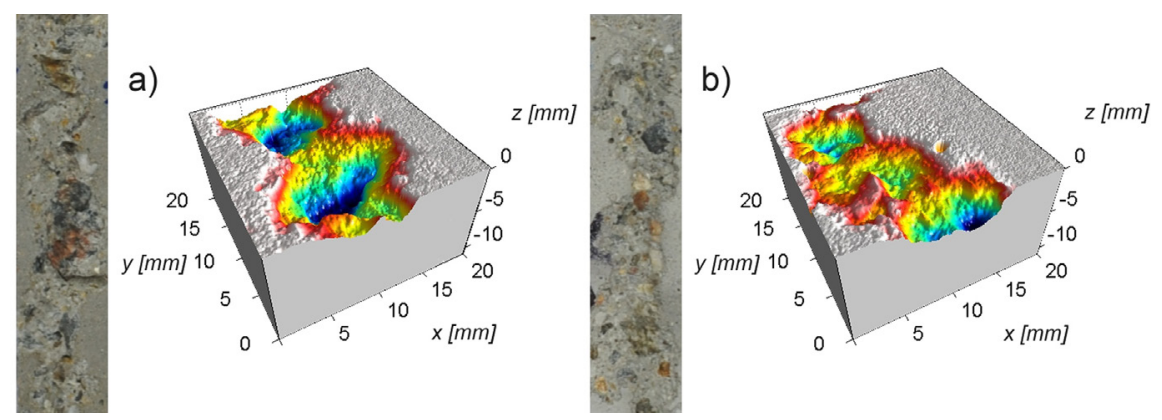

Fig. 9. Photograph and $3 D$ view of the groove created by a) the $C W J$ in reference and, b) $C N T /$ concrete composite sample (operating pressure $p=40 \mathrm{MPa}$, traversing velocity $v_{T R}=100 \mathrm{~mm} \cdot \mathrm{s}^{-1}$ )

\section{DISCUSSION}

Generally, higher differences in the resistance of tested samples to the action of both PWJs and CWJs can be observed at operating pressure of $20 \mathrm{MPa}$. Material removal rate obtained in $\mathrm{CNT} /$ concrete composite samples was ranging from $69 \%$ to $94 \%$ compared to reference in case of PWJs. Reference material removal rate (obtained in reference sample) at certain traversing velocity was taken as $100 \%$. Results of material removal rate for CWJs was ranging from 27 $\%$ to $83 \%$. Whereas PWJs created deeper grooves and was able to remove also larger stone grains from the cement matrix, CWJs was able to remove only upper layer of cement matrix and only some small stone grains.

Similar results were observed at the operating pressure of $40 \mathrm{MPa}$. Material removal rate for PWJs in $\mathrm{CNT} /$ concrete composite samples was within the range $78 \%$ to $99 \%$ compared to reference. Results of material removal rate for CWJs was ranging from $25 \%$ to $93 \%$ at this pressure. Again, PWJs created deeper grooves and was able to remove also larger stone grains from the cement matrix compared to CWJs.

Results obtained in the above described experiment seems to indicate that the CNT/concrete composite exhibits higher resistance than reference concrete to the action of both PWJs and CWJs under the given testing conditions. This can be ascribed most likely to the fact that adding of CNTs to the cement matrix changes its properties in a way, which results in its higher resistance to the action of both PWJs and CWJs. Because no significant changes in properties of the CNT/concrete composite with respect to the reference samples were observed (see above), additional tests performed using cement paste and cement paste with CNTs will be necessary to verify that addition of CNTs into the cement paste can significantly change its resistance to the action of water jets.

\section{CONCLUSIONS}

First results of the study aimed at the determination of possible influence of addition of CNTs to the concrete on its resistance to the action of continuous and pulsating water jets presented in the paper lead to following conclusions:

- Physical-mechanical properties of reference and $\mathrm{CNT} /$ concrete did not differ significantly after 7 days. In addition, test specimens characterization using X-ray powder diffraction and scanning electron microscopy did not reveal any significant differences in the structure of reference and CNT/concretes.

- Regardless the above-mentioned facts, the experiments proved that $\mathrm{CNT} /$ concrete composite exhibits higher resistance than reference concrete to the action of both PWJs and CWJs under the given testing conditions. This indicate that adding of CNTs to the cement matrix changes its properties in a way, which results in its higher resistance to the action of both PWJs and CWJs.

- To be able to explain this higher resistance of $\mathrm{CNT} /$ concrete composite compared to reference concrete, upcoming studies should be oriented at the determination of the influence of the CNTs on the hydration process XRPD and SEM/TEM on cement paste with addition of CNTs only before continuation of tests on concrete samples after 28 days. In addition, water-jetting tests will be performed on CNTs/cement paste samples to verify findings of the presented study. 


\section{ACKNOWLEDGEMENTS}

The work was performed under the support of the project of the Czech Science Foundation "Study of methods of nanoparticles dispersion, determination of conditions for preventing their re-agglomeration for application in cement composites", reg. no. 15-23219S, the Institute of Clean Technologies for Mining and the Utilization of Raw Materials for Energy Use - Sustainability program, reg. no. LO1406 financed by the Ministry of Education, Youth and Sports of the Czech Republic, and the long-term conceptual development of the research institution RVO: 68145535 . The work was partially supported also by the Ministry of Education, Youth and Sports of Czech Republic (project reg. no. SP2016/67). The authors are thankful for the support.

\section{REFERENCES}

[1] Li, Q., Liu, J., Xu, S. (2015). Progress in research on carbon nanotubes reinforced cementitious composites. Advances in Materials Science and Engineering, vol. 2015, p. 1-16, DOl:10.1155/2015/307435.

[2] Foldyna, J., Foldyna, V., Zeleňák, M. (2016). Dispersion of carbon nanotubes for application in cement composites. Procedia Engineering, vol. 149, p. 94-99, D0I:10.1016/j. proeng.2016.06.643.

[3] Sitek, L., Bodnarova, L., Soucek, K., Stas, L., Gurkova, L. (2015) Analysis of inner structure changes of concretes exposed to high temperatures using micro X-ray computed tomography. Acta Geodynamica et Geomaterialia, vol. 12, no. 1(177) p. 79-89, D0I:10.13168/AGG.2015.0009.

[4] Okeil, A.M., El-Tawil, S., Shahawy, M. (2001). Short-term tensile strength of carbon-fiber-reinforced polymer laminates for flexural strengthening of concrete girders. ACI Structural Journal, vol. 98, no. 4, p. 470-478.

[5] Lim, T.Y., Paramasivam P., Lee, S.L. (1987). Analytical model for tensile behavior of steel-fiber concrete. ACl Materials Journal, vol. 84, no. 4, p. 286-298.

[6] Neville, A. M.,Brooks, J.J. (1987). Concrete Technology. Longman Scientific \& Technical, Harlow.
[7] Balaguru, N.P., Shah, S.P. (1992). Fiber-reinforced cement composites. McGraw-Hill, New York.

[8] Xu, S., Li, Q. (2009). Theoretical analysis on bending behaviour of functionally graded composite beam crack-controlled by ultrahigh toughness cementitious composites. Science in China Series E: Technological Sciences, vol. 52, no. 2, p. 363378, D0l:10.1007/s11431-008-0337-9.

[9] Li, V.C., Leung, C.K.Y. (1992). Steady-state and multiple cracking of short random fiber composites. Journal of Engineering Mechanics, vol. 118, no. 11, p. 2246-2264, DOI:10.1061/(ASCE)0733-9399(1992)118:11(2246).

[10] P.,carbon--Zweben, C. (1968). Tensile failure of fiber composites. AlAA Journal, vol. 6, no. 12, p. 2325-2331, DOI:10.2514/3.4990.

[11] lijima, S. (1991). Helical microtubules of graphitic carbon. Nature, vol. 354, p. 56-58, D0l:10.1038/354056a0.

[12] Kang, S., Seo, J., Park, S. (2015). The characteristics of CNT/ cement composites with acid-treated MWCNTs. Advances in Materials Science and Engineering, vol. 2015, p. 1-9, DOI:10.1155/2015/308725.

[13] Grobert, N. (2007). Carbon nanotubes - becoming clean. Materials Today, vol. 10, no. 1-2, p. 28-35, Dol:10.1016/ S1369-7021(06)71789-8.

[14] Popov, V.N. (2004). Carbon nanotubes: properties and application. Materials Science and Engineering: R: Reports, vol. 43, no. 3, p. 61-102, D0l:10.1016/j.mser.2003.10.001.

[15] Sitek, L., Foldyna, J., Martinec, P., Ščučka, J., Bodnárová, L., Hela, R. (2011). Use of pulsating water jet technology for removal of concrete in repair of concrete structures. The Baltic Journal of Road and Bridge Engineering, vol. 6, no. 4, p. 235242, D0I:10.3846/bjrbe.2011.30.

[16] EN 12350-2 Testing of fresh concrete - Part 2: Slump-test. European standard.

[17] EN 12390-3 Testing hardened concrete - Part 3: Compressive strength of test specimens. European standard.

[18] EN 12390-5 Testing hardened concrete - Part 5: Flexural strength of test specimens. European standard.

[19] Foldyna, J., Svehla, B. (2011). Method of Generation of Pressure Pulsations and Apparatus form Implementation of This Method. US patent no. 7,934,666, USPTO, Aleksandria.

[20] Foldyna, J., Sitek, L., Ščučka, J., Martinec, P., Valíčicek, J., Páaleníikováa, K. (2009) Effects of pulsating water jet impact on aluminium surface. Journal of Materials Processing Technology, vol. 209, no. 20, p. 6174-6180, D0l:10.1016/j. jmatprotec.2009.06.004. 